\title{
Reduced STMN1 expression induced by RNA interference inhibits the bioactivity of pancreatic cancer cell line Panc-1
}

\author{
J. LI' ${ }^{1}$, G. H. HU' ${ }^{1}$, F. J. KONG ${ }^{2}$, K. M. WU' ${ }^{1}$, B. $\mathrm{HE}^{1}$, K. SONG ${ }^{1}$, W. J. SUN ${ }^{1, *}$ \\ ${ }^{1}$ Department of General Surgery, Xiangya Hospital, Central South University, Changsha, China; ${ }^{2}$ Department of Anesthesiology, Xiangya Hospital, \\ Central South University, Changsha, China
}

*Correspondence: sunweijia2013@126.com

Received May 4, 2013 / Accepted July 1, 2013

\begin{abstract}
Increased expression of STMN1 has been observed in many tumor forms, but its expression and potential biological role in pancreatic cancer is still unknown. In this study, we demonstrated that STMN1 was expressed to a large extent in pancreatic cancer tissues and cell lines as compared to normal pancreatic tissues. Suppression of STMN1 expression via transfection with STMN1-specific siRNA could not only significantly inhibit the proliferation, migration and invasion ability of Panc-1 cells, but also enhance the apoptosis of Panc-1 cells. In addition, downregulation of STMN1 obviously enhanced the acetylation level of $a$-tubulin. All these results indicated that STMN1 plays an important role in pancreatic cancer development, and might serve as a potential therapeutic target for pancreatic cancer.
\end{abstract}

Key words: pancreatic cancer, STMN1, Panc-1, RNA interference (RNAi), cancer therapy

Pancreatic cancer is the most lethal of the solid tumors and the fourth leading cause of cancer-related death in the USA[1]. Both the morbidity and mortality of pancreatic cancer have been rising gradually. In 2012, it was estimated that there were over 43,920 new cases with pancreatic cancer and over 37,390 deaths attributed to it in the United States[2]. The major reason for this high mortality rate is its highly aggressive nature and the limited effect of standard chemotherapy and radiotherapy [3]. Therefore, studies are urgently needed in order to investigate the mechanisms of pancreatic cancer and search for more effective treatments.

Stathmin1(STMN1), also named as oncoprotein 18, metablastin, phosphoprotein 19 and LAP18[4], is encoded by the human STMN1 gene located at chromosome 1 , band p35-36.1[5]. It is a ubiquitous cytosolic phosphoprotein that can regulate microtubule dynamics by depolymerizing microtubules through both the sequestration of $\alpha / \beta$-tubulin heterodimers and the enhancement of microtubule catastrophe[6]. As an important microtubule-destablizing protein, STMN1 has already been found to be involved in the regulation of cell proliferation, apoptosis, differentiation and motility[7-12]. Furthermore, it has been reported that STMN1 was highly expressed in a wide scale of human cancers including leukemia, breast, lung, oral squamous cell, prostate, nasopharynx, endometrium, diffuse type stomach, colorectum, pelvic serous, and liver[13-25], suggesting that STMN1 plays a crucial role in tumorigenesis and may be a key anti-oncogene in tumors. However, no data is available regarding the role of STMN1 in pancreatic cancer cells.

Thus, to identify the role of STMN1 in the malignant properties of pancreatic cancer cells, we performed this study to investigate the effects of siRNA-mediated STMN1 downregulation on the proliferation, apoptosis, migration and invasion of Panc-1 cells as well as microtubule dynamics.

\section{Materials and methods}

Tissue specimen collection. Twenty-one primary pancreatic ductal adenocarcinoma specimens and matched adjacent normal pancreatic tissues (taken $>2 \mathrm{~cm}$ from the tumor margin) were collected from patients undergoing treatment at the Department of General Surgery, Xiangya Hospital, Central South University, China. Six normal pancreatic samples were collected at surgery from patients suffering from acute pancreatic injury. Patients were histopathologically diagnosed 
as having primary pancreatic ductal adenocarcinoma, who were newly diagnosed and untreated, or had no history of other tumor. All samples were obtained immediately following surgical removal, snap-frozen in liquid nitrogen, and stored at $-80^{\circ} \mathrm{C}$ until use. Informed consent was obtained from all patients in accordance with the guidelines of Central South University, and the study protocols were approved by the Ethics Committee of Central South University.

Cell lines and cell culture. The human pancreatic cancer cell lines CFPAC-1, Panc-1, and BxPC-3 (Institute of Biochemistry and Cell Biology, Shanghai) were maintained in our laboratory and cultured in H-DMEM medium containing $10 \%$ FBS (Gibco Laboratories, USA). Cells were cultured at $37^{\circ} \mathrm{C}$ in $5 \% \mathrm{CO}_{2}$.

Small interfering RNA transfection. The small interfering RNA (siRNA) targeting STMN1 gene and negative control siRNA were obtained from SANTA CRUZ (sc36127). The siRNA transfection was performed using Lipofectamine 2000 (Invitrogen) according to the manufacturer's instructions. Briefly, the pancreatic cancer cells were seeded in a six-well plate at a density of $2 \times 10^{5}$ cells $/$ well and incubated until $~ 80 \%$ confluence. The cells were washed twice with phosphatebuffered solution (PBS) and then Opti-MEM I reduced serum medium (Invitrogen) was added to each well. Then siRNA and Lipofectamine 2000 were mixed gently and incubated together in Opti-MEM I reduced serum medium at room temperature for $20 \mathrm{~min}$ to form siRNA-Lipofectamine complex. The cells were incubated in the siRNA-Lipofectamine complex-containing medium for $6 \mathrm{~h}$, then the medium was replaced with H-DMEM medium containing 10\% FBS. The cells continued to be incubated for $48 \mathrm{~h}$ and then harvested for further assays. A sequence non-specific to any known gene was used as the negative control-siRNA (Scramble group).

Real-time PCR. Total cellular RNA was extracted from the 21 pancreatic cancer tissues and their adjacent noncarcinoma tissues, the six normal pancreatic tissues and the cultured cells using Trizol reagent (Invitrogen) for reverse transcription. RNA was synthesized to cDNA using the RevertAid H Minus First Strand cDNA Synthesis Kit (Fermentas, Vilnius, Lithuania) in accordance with the manufacturer's instructions. RT-PCR assays were carried out using SYBR Green PCR Master Mix (Bio-Rad, USA) and RTPCR amplification equipment using specific primers, which were synthesized using ProMab (Shanghai, China). The following primers were used for the amplification of STMN1: sense primer 5'-TCAGCCCTCGGTCAAAAGAAT-3' and antisense primer 5'-TTCTCGTGCTCTCGTTTCTCA-3'. Glyceraldehyde phosphate dehydrogenase (GAPDH) was amplified as an internal control using sense primer 5'ACAACTTTGGTATCGTGGAAGG-3' and antisense primer 5'-GCCATCACGCCACAGTTTC-3'. Briefly, reverse transcription was performed in a final volume of $20 \mu \mathrm{L}$ containing $2 \mu \mathrm{g}$ of total RNA sample, $1 \mu \mathrm{L}$ Oligo(dT) 18 primer, $4 \mu \mathrm{L} 5 \times$ reaction buffer, $2 \mu \mathrm{L}$ dNTP mix, $0.5 \mu \mathrm{L}$ Ribonuclease Inhibitor, $1 \mu \mathrm{L}$ RevertAidTM M-MulV Reverse Transcriptase, and
$11 \mu \mathrm{L}$ DEPC-treated water. Real time PCR contained a total reaction volume of $25 \mu \mathrm{L}$ containing cDNA, $2 \times$ SYBR Green PCR Mastermix, primers, and nuclease-free water. The reaction was first denatured at $95^{\circ} \mathrm{C}$ for $2 \mathrm{~min}$, then 40 cycles at $94{ }^{\circ} \mathrm{C}$ for $30 \mathrm{~s}, 60^{\circ} \mathrm{C}$ for $30 \mathrm{~s}$, and followed by $72{ }^{\circ} \mathrm{C}$ for $30 \mathrm{~s}$. Independent experiments were repeated three times for each sample and the relative expression levels of genes were analyzed through the use of the $2^{-\Delta \Delta C t}$ method[26].

Western blot. The total cellular protein was extracted through the use of the Total Protein Extraction Kit (ProMab); an equal amount of the protein was separated on 10\% SDSPAGE. The total protein was transferred to nitrocellulose membranes (Pierce, Rockford, USA) and incubated overnight at $37^{\circ} \mathrm{C}$ with rabbit anti-STMN1 polyclonal antibodies $(1: 1500$; ABCCam, USA), mouse $\alpha$-tubulin antibodies (1:150; Abcam), mouse acetylated $\alpha$-tubulin antibody (1:150; Abcam), or Mouse GAPDH antibody (1:15000; Santa Cruz, USA). After washing it for $2 \times 3 \mathrm{~min}$, the membrane was incubated with secondary antibodies for $1 \mathrm{~h}$ at room temperature and colored using ESL. The membrane was scanned for the relative value of protein expression in gray scale by Image-Pro plus software 6.0 (Media Cybernetics, Sliver Spring, USA). The relative levels of target protein were represented as the density ratio versus GAPDH, and the acetylation level of $\alpha$-tubulin was represented as the relative level of acetylated $\alpha$-tubulin protein versus the relative levels of $\alpha$-tubulin protein.

Cell proliferation and viability assay. For the cell proliferation assay, Panc- 1 cells and Panc- 1 cells transfected steadily with STMN1-siRNA or negative control-siRNA were seeded in a 6-well plate at a concentration of $1 \times 10^{4}$ cells/well. The cell cultures were measured for cell proliferation levels at different time points (1, 2, 3, 4 and 5 days) using a hemacytometer. To measure cell viability, Cells were plated in 96-well plates at a density of about $1 \times 10^{4}$ cells per well. After treatment, the plates were incubated in a $37^{\circ} \mathrm{C}$ humidified incubator for 12 , 24,48 or $72 \mathrm{~h}$ after siRNA transfection, then an MTT assay was performed according to the manufacturer's manual (Sigma, St Louis, USA). Briefly, at the end of treatment, $50 \mu \mathrm{L} 5 \mathrm{mg} / \mathrm{ml}$ MTT reagent in PBS was added to each well, and the cells were incubated for another $4 \mathrm{~h}$ at $37^{\circ} \mathrm{C}$. Subsequently, the supernatant was removed and $150 \mu \mathrm{L}$ of DMSO (Sigma) was added to each well. Optical density (OD) was determined by measuring the absorbance at $570 \mathrm{~nm}$ using a Victor 3 spectrofluorimeter (Perkin Elmer, Foster City, USA) 12, 24, 48, 72 hours after transfection. Each assay was performed in triplicate and each experiment was repeated at least three times.

Cell migration and invasion assays. The cell invasion assays were performed in a 24-well transwell chamber (Corning Inc., Corning, NY, USA), which contained an $8 \mu \mathrm{m}$ pore size polycarbonate membrane filter and was precoated with $100 \mu \mathrm{g}$ Matrigel (Becton-Dickinson, Bedford, USA) for the invasion assay. The STMN1-siRNA Panc-1 cells, control-siRNA Panc-1 cells, and Panc- 1 cells were collected and resuspended in the serum-free H-DMEM medium at a concentration of $1 \times 10^{5}$ cells $/ \mathrm{ml}$, respectively. Then the cell suspensions were added 
into the upper chambers ( $200 \mathrm{ml} /$ well), and the bottom chambers were filled with H-DMEM medium containing $10 \% \mathrm{FBS}$ $\left(500 \mathrm{ml} /\right.$ well), followed by a $24 \mathrm{~h}$ incubation at $37^{\circ} \mathrm{C}$. The cells that did not penetrate the polycarbonate membrane were swabbed using cotton bud, then the cells transmembraned through and adhered to the bottom of polycarbonate membrane were stained with a solution containing $0.1 \%$ crystal violet and 20\% methanol for $20 \mathrm{~min}$, and were photographed under an Olympus fluorescence microscope and counted manually. The migration assay was done in a similar manner but without the Matrigel coating on the filters. Two independent experiments were done for each assay. Five fields were randomly selected and the number of trans-membrane cells was counted. The experiment was repeated twice with triplicate measurements in each experiment.

Flow cytometry assay (FCM). Apoptotic cells were differentiated from viable or necrotic ones by combined application of annexin V-FITC and PI (BD Biosciences Clontech, USA). Apoptotic and necrotic cells were distinguished on the basis of annexin V-FITC reactivity and PI exclusion. The samples were washed twice and adjusted to a concentration of $1 \times 10^{5}$ cells $/ \mathrm{mL}$ with $4{ }^{\circ} \mathrm{C}$ PBS. The Falcon tubes $(12 \mathrm{~mm} \times 75 \mathrm{~mm}$, polystyrene round-bottom) were used in this experiment.
$500 \mu \mathrm{L}$ of suspensions was added to each labeled tube, $5 \mu \mathrm{L}$ of Annexin V-FITC and $5 \mu \mathrm{L} 5 \mu \mathrm{g} / \mathrm{mL}$ PI were also added to the labeled tubes, and incubated for at least $20 \mathrm{~min}$ at room temperature in the dark. Then $400 \mu \mathrm{L}$ of PBS binding buffer was added to each tube without washing and analyzed using flow cytometry (BD, San Jose, CA, USA) as soon as possible (within 1h).

Statistical analysis. All the values were expressed as mean \pm SD. Statistical analysis was performed using the SPSS (version 13.0, Chicago, IL). Data for STMN1 mRNA expression in fresh specimens were analyzed using the Mann-Whitney U-test. The statistical correlation of data between experimental and control groups was analyzed by one way ANOVA. In any case, $\mathrm{P}<0.05$ was considered with statistical significance.

\section{Results}

STMN1 was overexpressed in pancreatic cancer tissues and cell lines. To determine whether or not the expression of STMN1 is upregulated in pancreatic cancer, we first measured the STMN1 expression level in fresh clinical samples using quantitative real-time RT-PCR and western bloting assay. As shown in Fig.1A and Fig.1C, both mRNA and protein

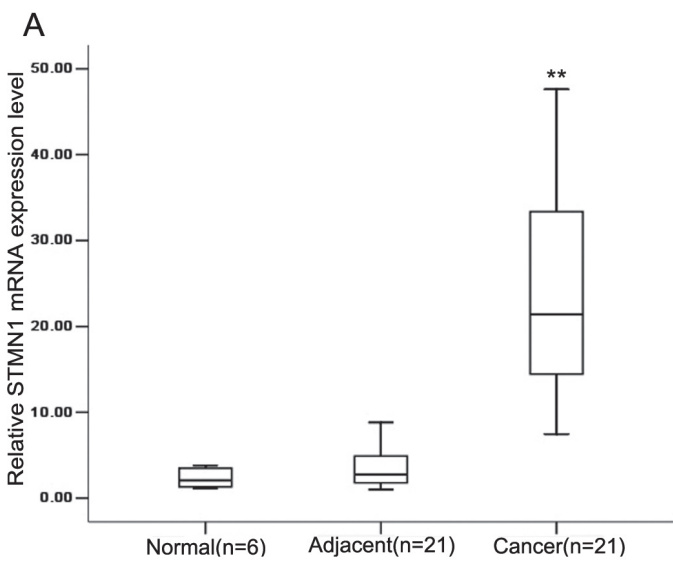

C

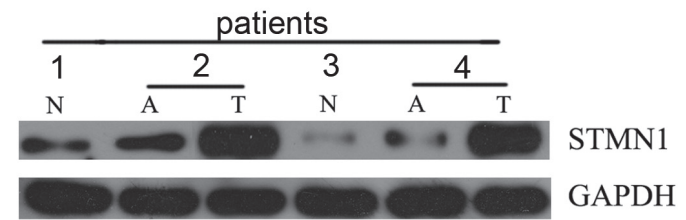

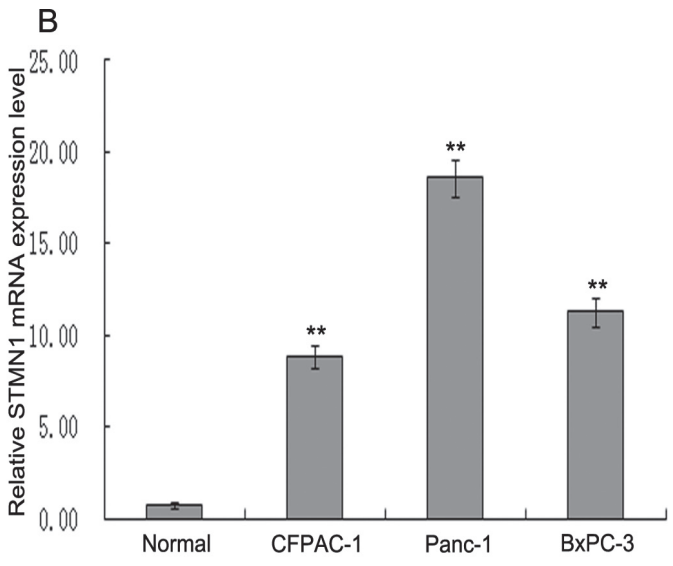

D

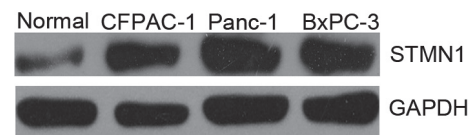

Figure 1. Detection of STMN1 in pancreatic cancer tissue and cell lines by RT-PCR and Western blot.

RT-PCR and Western blot were performed to determine the expression of STMN1 in pancreatic cancer tissues and cell lines. A. Relative STMN1 mRNA expression level in different tissue. cancer: pancreatic cancer tissue; adjacent: adjacent non-tumor tissue; normal: six normal pancreatic tissues. Boxes represent the medians and interquartile ranges of the normalized threshold values. B. Relative STMN1 mRNA expression level in six normal pancreatic tissue and in pancreatic cancer cell lines CFPAC-1, Panc-1 and BxPC-3. STMN1 mRNA expression levels were calculated by the $2^{-\Delta \Delta C t}$ method and normalized to GAPDH mRNA. C. It is a representative western blot analysis of STMN1 expression in all specimens. N: normal pancreatic tissue; A: adjacent non-tumor tissue; T: pancreatic cancer tissue. $D$. It is a representative western blot analysis of STMN1 expression in pancreatic cancer cell lines. Normal: normal pancreatic tissue; CFPAC-1: CFPAC-1 cells; Panc-1: Panc-1 cells; BxPC-3: BxPC-3 cells. ${ }^{* *}$ means that P<0.01. 
expression levels of STMN1 in pancreatic cancer samples were higher than those of adjacent non-tumor tissues and normal pancreatic tissues $\left({ }^{*} \mathrm{P}<0.01\right)$. Moreover, we also detected STMN1 expression in three common pancreatic cancer cell lines. Our data showed that all three pancreatic cancer cell lines exhibited upregulated mRNA and protein expression of
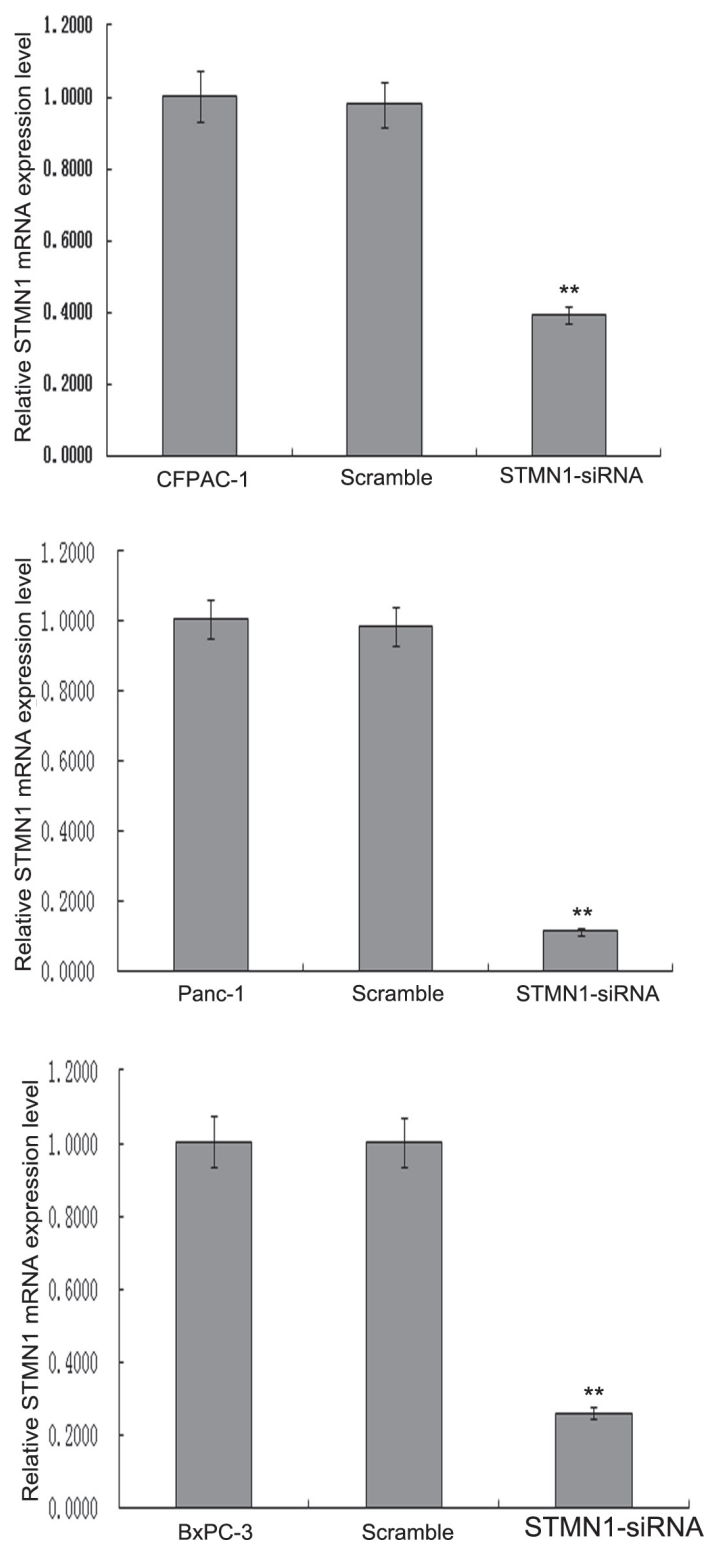

Figure 2. Detection of STMN1 after transfection by RT-PCR. RT-PCR was performed to determine the expression of STMN1 after transfection. A, B and C represent the STMN1 mRNA expression in pancreatic cancer cell line CFPAC-1, Panc-1 and BxPC-3 48h after transfection with STMN1-siRNA or negative control RNA, respectively. Data are presented as mean \pm SD. ${ }^{* *} \mathrm{P}<0.05$, compared with the Scramble group or the black control group. CFPAC-1, Panc-1 or BxPC-3: CFPAC-1, Panc-1 or BxPC-3 cells; Scramble : CFPAC-1, Panc- 1 or BxPC-3 cells transfected with negative control siRNA; STMN1-siRNA: CFPAC-1, Panc-1 or BxPC-3 cells transfected with STMN1-specific siRNA.
STMN1 as compared with normal pancreatic tissues (Fig. 1B and Fig. $\left.1 \mathrm{D},{ }^{*} \mathrm{P}<0.01\right)$. Altogether, these findings indicated that STMN1 may be involved in the tumorgenesis of pancreatic cancer.

STMN1-siRNA effectively inhibited STMN1 mRNA expression. To detect the RNAi efficiency of STMN1-specific siRNA to the three commonly used pancreatic cancer cell lines CFPAC-1, Panc- 1 and BxPC-3, the STMN1 mRNA expression was examined $48 \mathrm{~h}$ after transfection with STMN1-specific siRNA. As shown in Fig. 2, the expression of STMN1 mRNA was significantly inhibited in all three pancreatic cell lines $\left({ }^{*} \mathrm{P}<0.05\right)$. However, the RNAi efficiency was highest in Panc1 ( $88.9 \%$ vs $61.7 \%$ and $74.3 \%$ ). Therefore, Panc- 1 was chosen for the subsequent experiments.

STMN1-siRNA obviously inhibited STMN1 protein expression in Panc-1 cells. The protein level of STMN1 in Panc- 1 cells $48 \mathrm{~h}$ after transfection was detected through the western blot method. The result indicated that STMN1-siRNA significantly inhibited the protein level of STMN1 in Panc-1 cells, when compared with Scramble or Panc-1 group cells (Fig. $3,{ }^{* \star} \mathrm{P}<0.01$ ).

STMN1 suppression retarded proliferation and viability of Panc- 1 cells. Cell counting assay was performed to determine the effect of forced suppression of STMN1 on cell proliferation. As shown in the growth curve in Fig. 4A, the STMN1-siRNA group significantly reduced cell proliferation as compared with the Scramble or Panc-1 group $(\mathrm{P}<0.05)$. Morever, MTT assay revealed that the cell viability of Panc-1 cells transfected with STMN1-siRNA was significantly de-
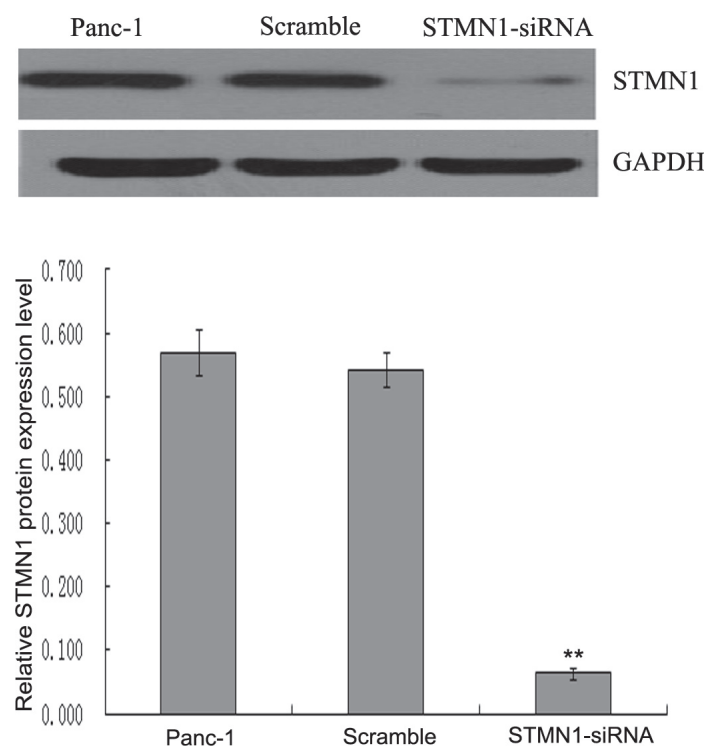

Figure 3. Detection of STMN1 after transfection by Western Blot. Western Blot was used to determine the protein expression of STMN1 after transfection in Panc-1 cells. ${ }^{*} \mathrm{P}<0.01$, compared with the Scramble group or the black control group. Panc-1: Panc-1 cells; Scramble: Panc-1 cells transfected with negative control siRNA; STMN1-siRNA: Panc-1 cells transfected with STMN1-specific siRNA. 

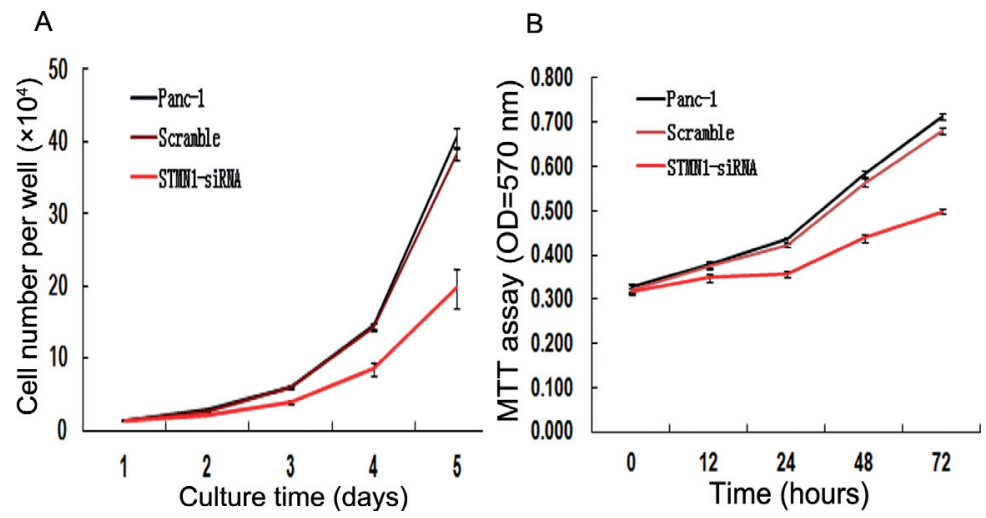

Figure 4. Effect of STMN1 suppression on cell proliferation and viability of Panc-1 cells

Cell counting assay and MTT assay were performed to detected the cell proliferation and viability of Panc-1 cells after transfection, respectively. A: Cell counting assay showed the growth curves of cells stably transfected Panc-1 cells. B: MTT assay. The cell proliferation and viability of Panc-1 cells transfected with STMN1-siRNA was significantly decreased as compared with the Scramble or Panc-1 group cells. Data represent the mean \pm SD of the three independent experiments performed in triplicate. Panc-1: Panc-1 cells; Scramble: Panc-1 cells transfected with negative control siRNA; STMN1-siRNA: Panc-1 cells transfected with STMN1-specific siRNA.
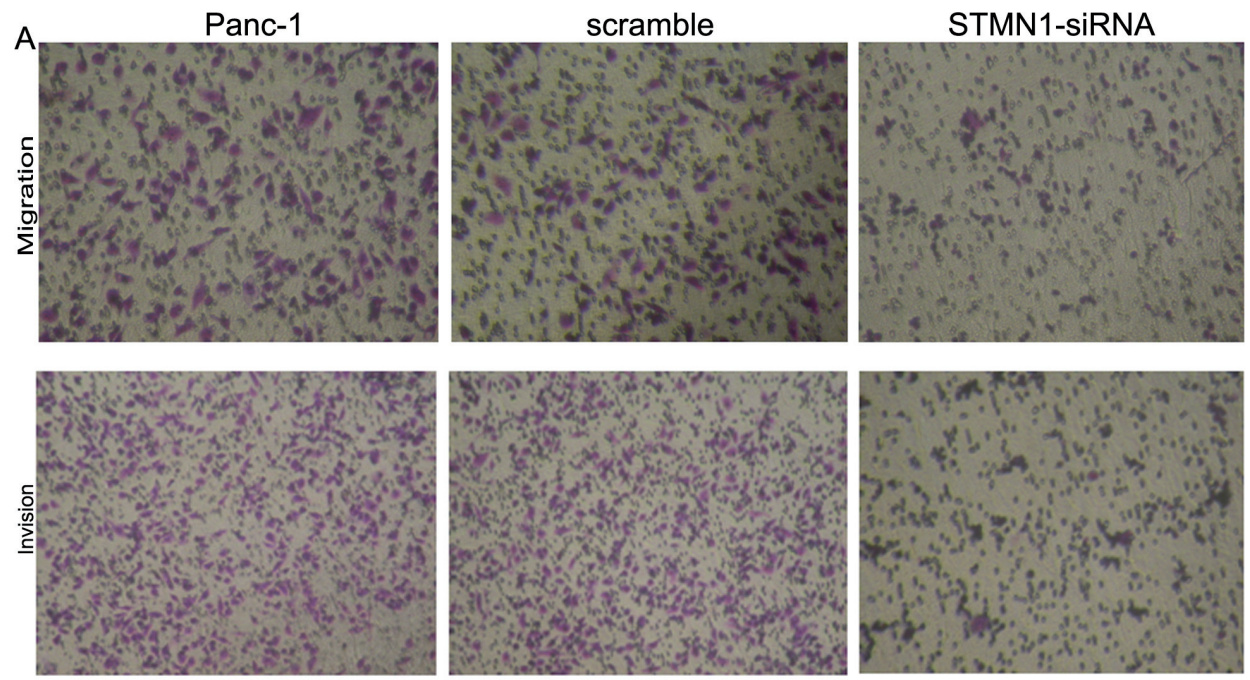

B Migration

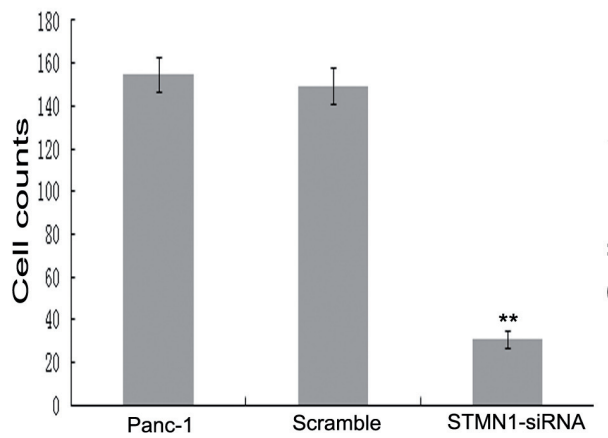

C Invision

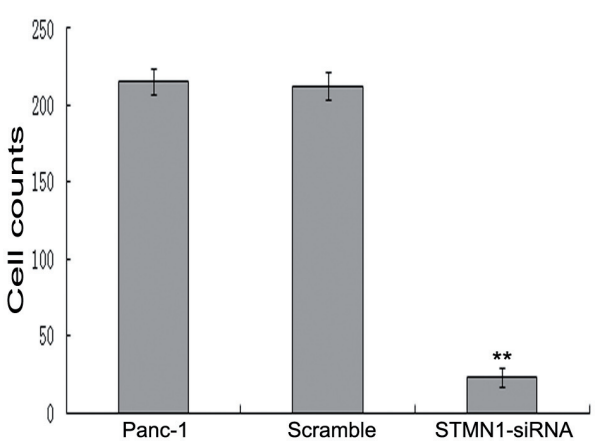

Figure 5. Effect of STMN1 suppression on migration and invasion of Panc-1 cells.

Transwell assay was performed to determine the effect of forced suppression of STMN1 on cell migration and invasion ability of Panc-1 cells. A. Migrating and invading cells are stained with crystal violet and visualized by microscopy (original magnification $\times 200$ ). $B$. The average number of migrating or invading cells per field, Bars, mean \pm SE. ${ }^{* *} \mathrm{P}<0.01$, compared with the Scramble or Panc-1 group. Panc-1: Panc-1 cells; Scramble: Panc-1 cells transfected with negative control siRNA; STMN1-siRNA: Panc-1 cells transfected with STMN1-specific siRNA. 
creased when compared with the Scramble or Panc-1 group cells $(\mathrm{P}<0.05$, Fig. 4B).

STMN1 suppression inhibited the migration and invasion ability of Panc-1 cells. The Transwell assay revealed that Panc-1 cells transfected with STMN1-siRNA had much lower migratory ability and invasive activity than the Scramble or Panc-1 group cells $\left({ }^{* *} \mathrm{P}<0.01\right)$. This data indicated that suppression of STMN1 has a direct inhibitory effect on the migration and invasion capacity of Panc-1 cells (Fig. 5).

STMN1 suppression enhanced Panc- 1 cell apoptosis. We performed Annexin V/PI flow cytometry assay analysis on Panc-1 cells of Panc-1 group, Scramble group and STMN1siRNA group. As shown in the Fig. 6, the rate of apoptotic Panc-1 cells was higher in the STMN1-siRNA group than in the Scramble group or Panc-1 group $\left({ }^{*} \mathrm{P}<0.01\right)$. These results suggested that STMN1-siRNA enhances Panc-1 cell apoptosis.

STMN1-siRNA enhanced the stabilization of MT in Panc-1 cells. STMN1 is a MT destabilizing protein. Stable MTs can be distinguished by a variety of post-translational modifications, such as acetylation, polyglutamylation, and detyrosination[27], all recognizable with specific antibodies. To further elucidate the probable mechanism of STMN1siRNA-mediated biological change, we explored the effect of siRNA-mediated downregulation of STMN1 on the amount of acetylated $\alpha$-tubulin and $\alpha$-tubulin in Panc- 1 cells by western blot, and then the acetylation level of $\alpha$-tubulin in Panc- 1 cells $48 \mathrm{~h}$ after transfection was analyzed. As shown in the Fig. 7, the acetylation level of $\alpha$-tubulin in STMN1-siRNA group was significantly higher than the Scramble group or Panc-1 group $\left.{ }^{*} \mathrm{P}<0.01\right)$. These results suggested that $\mathrm{STMN1}$-siRNA enhanced the stabilization of MT in Panc- 1 cells.

\section{Discussion}

The prognosis of patients suffering from pancreatic cancer is still poor and new and pioneering therapeutic options are urgently required. STMN1 not only plays an important role in cell mitosis and motility but also participates as a "relay protein" in several intracellular cancer related signaling
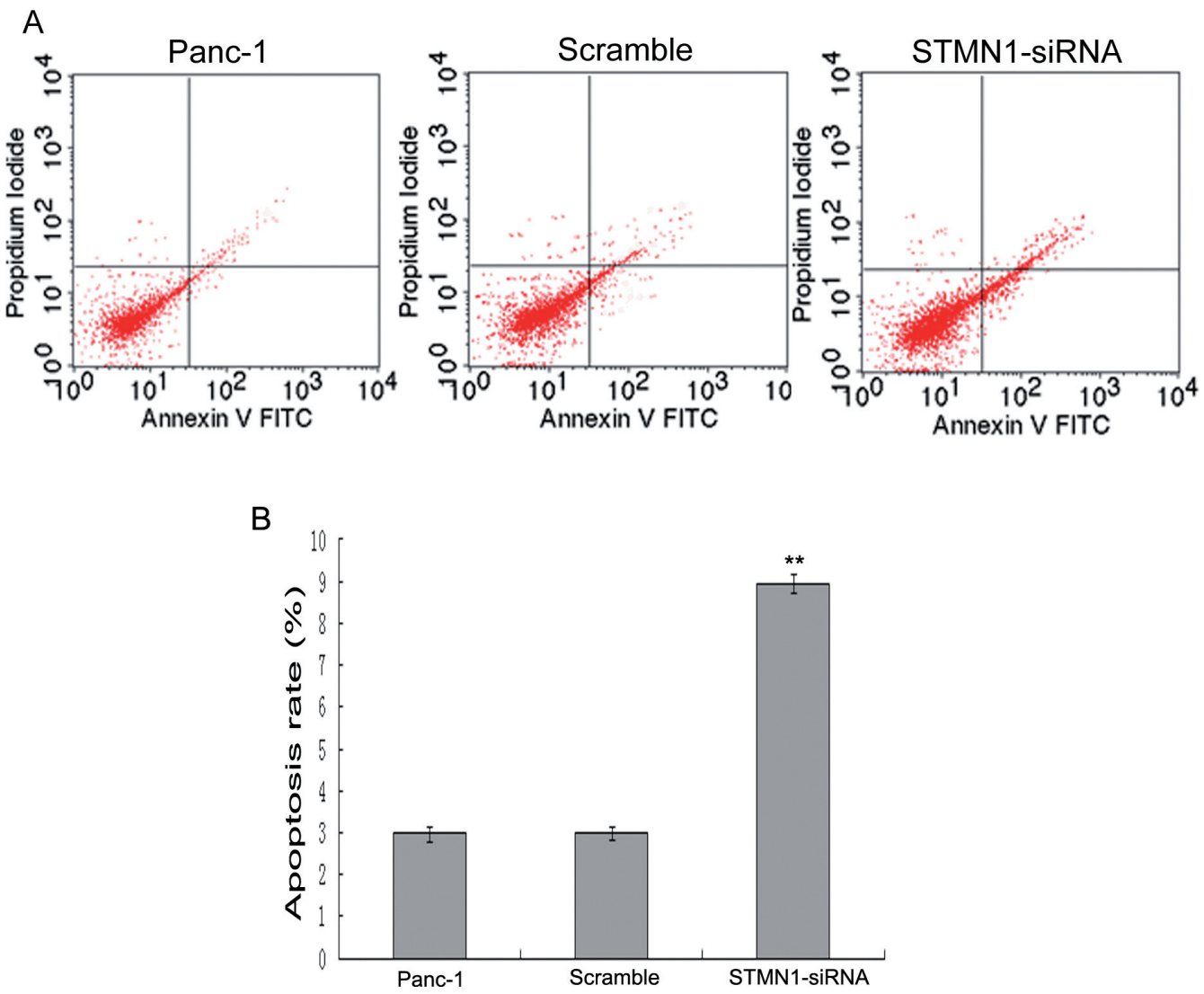

Figure 6. Effect of STMN1 suppression on apoptosis of Panc-1 cells.

FCM assay was performed to determine the effect of forced suppression of STMN1 on cell apoptosis of Panc-1 cells. A. The cells were stained with annexin V-FITC. The right upper quadrant represents late apoptotic and necrotic cells; the right lower quadrant represents early apoptotic cells; the left upper quadrant represents cells that were mechanically injured; and the left lower quadrant represents normal proliferating cells. B. The apoptosis rate of Panc-1 cells after transfection in different group. Bars, (mean $\pm \mathrm{SE}$ )\%. ${ }^{\star \star} \mathrm{P}<0.01$, compared with the Scramble or Panc-1 group. Panc-1: Panc-1 cells; Scramble: Panc-1 cells transfected with negative control siRNA; STMN1-siRNA: Panc-1 cells transfected with STMN1-specific siRNA. 

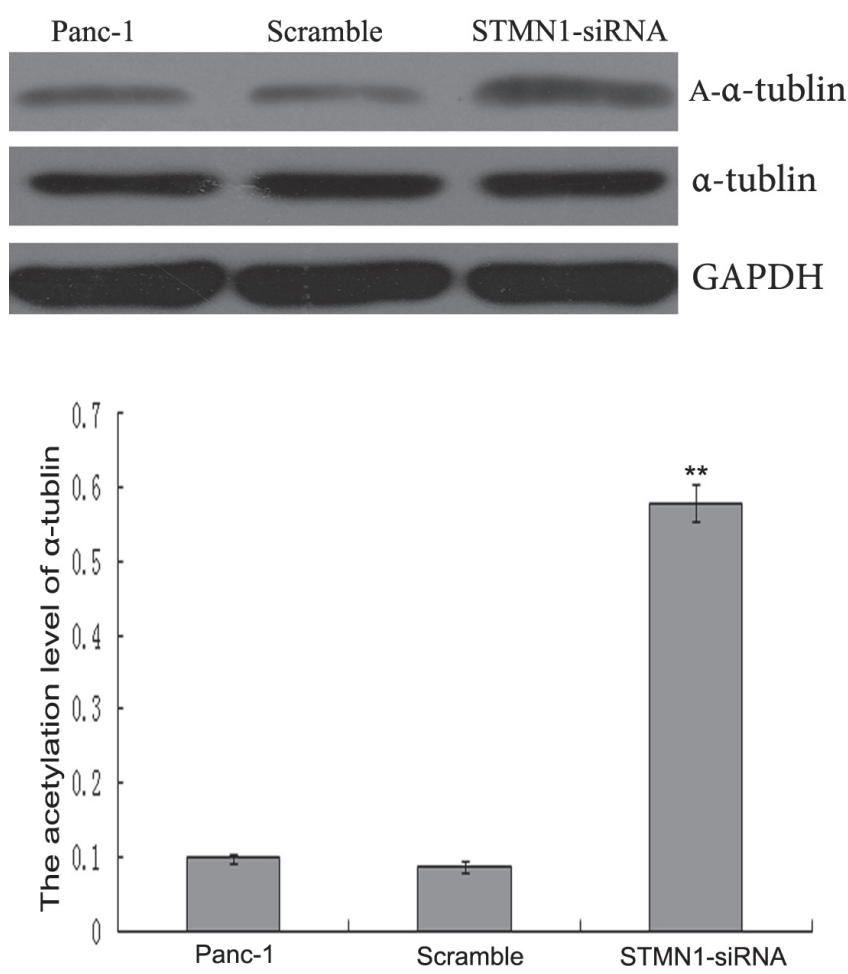

Figure 7. Effect of STMN1 suppression on the expression of acetylated $\alpha$-tubulin and $\alpha$-tubulin in Panc- 1 cells.

Western Blot was used to determine the effect of STMN1 suppression on the expression of acetylated $\alpha$-tubulin and $\alpha$-tubulin in Panc- 1 cells, GAPDH was used as internal loading controls (upper panel). the acetylation level of $\alpha$-tubulin was analyzed (lower panel), and the acetylation level of $\boldsymbol{\alpha}$-tubulin was represented as the relative level of acetylated $\boldsymbol{\alpha}$-tubulin protein versus the relative levels of $\alpha$-tubulin protein. ${ }^{*} \mathrm{P}<0.01$, compared with the Scramble or Panc-1 group. Panc-1: Panc-1 cells; Scramble: Panc-1 cells transfected with negative control siRNA; STMN1-siRNA: Panc-1 cells transfected with STMN1-specific siRNA.

pathways, such as the Hedgehog signaling pathway[9], PI3K pathway[28], p53 pathway[29] and so on. Dysfunction of STMN1 could lead to constant microtubule assembly and uncontrolled cell cycles, which would result in continuous abnormal cell growth -tumor formation. Furthermore, it was reported that STMN1 has already been found to be involved in the oncogenesis of a wide variety of human cancers $[9,30$, 31]. However, it is still unclear whether STMN1 contributes to pancreatic carcinogenesis or not. In this study, we investigated the role of STMN1 in pancreatic cancer cell proliferation, apoptosis, migration and invasion by RNAi technology.

Cell proliferation and apoptosis are important to the oncogenesis and chemotherapy resistance of pancreatic cancer cells. In this study, we analyzed the suppressive effect of Panc- 1 cell proliferation and apoptosis by siRNA silencing the STMN1 gene expression. Up to date, this is the first research that RNAi-mediated STMN1 expression was applied to inhibit pancreatic cancer cell proliferation and induce apoptosis, and this finding consists with the previous results that STMN1 promotes tumor proliferation and induces apoptosis in other malignancies[30-33].

It is well known that the poor prognosis of pancreatic cancer patients is mainly attributable to early invasion and distant metastases. The metastatic process includes a series of interdependent events, including cancer cell proliferation, migration and invasion. Cancer metastasis firstly requires that the tumor cell can obtain high motility ability. Previous studies have demostrated that STMN1 has been involed in the regulation of cell mobility, particularly cancer cell mobility [11, $24,31]$. In the experiment, we demonstrated that downregulation of STMN1 could inhibit the migration and invasion of Panc-1 cells, which indicated that STMN1 was involved in the metastatic capacity of pancreatic cancer.

Microtubules are protein polymers comprising $\alpha / \beta$ tubulin heterodimers, which contribute to and are essential for the structure and function of the cell. These functions include mitosis, intracellular transport, polarity, and cell motility[34, 35]. Dynamics of microtubule function can be best described as an alternating pattern of stabilization and destabilization. To further investigate the role of STMN1 in the regulation of microtubule dynamics, the acetylation level of $\alpha$-tubulin was also observed by Western blotting assay. Our study found that downregulation of STMN1 could enhanced the stabilization of MT in Panc-1 cells, indicating that the action of STMN1 in the development of pancreatic cancer is possibly via the regulation of microtubule dynamics.

However, our study has two limitations. In our study, it is shown that the RNAi efficiency of STMN1-siRNA to STMN1 mRNA expression was higher in Panc-1 cell line than in CFPAC- 1 and BxPC-3 cell line, and in order to obtain satisfactory results, we analyzed only the role of STMN1 in Panc-1 cell line post-transfection by STMN1-siRNA, but not in CFPAC-1 and BxPC-3 cell line simultaneously. Another limitation is that our study proved only that RNAi can inhibit STMN1 expression in vitro. Therefore, it needs further in vivo study to verify the effect and risk of STMN1 knockdown by STMN1-siRNA for pancreatic cancer therapy.

In summary, our results reveal that RNAi-mediated downregulation of STMN1 effectively inhibits the proliferation, migration and invasion of Panc-1 cells. Meanwhile, STMN1-siRNA can also enhance Panc-1 cell apoptosis. Furthermore, our study demonstrated also that the action of STMN1 in the development of pancreatic cancer is possibly via the rugulation of microtubule dynamics. All these findings indicated that STMN1 plays an important role in pancreatic cancer development, and might serve as a potential therapeutic target for pancreatic cancer. However, further studies are needed in vivo study to clarify the effect and risk of STMN1 knockdown by STMN1-siRNA for pancreatic cancer therapy and the exact mechanism of how STMN1 is involved in pancreatic cancer cell proliferation and motility.

Acknowledgements: This work was supported by the Fundamental Research Funds of the Central Universities of Central South University. 


\section{References}

[1] JEMAL A, SIEGEL R, XU J, WARD E. Cancer statistics, 2010. CA Cancer J Clin 2010; 60: 277-300. http://dx.doi. org/10.3322/caac. 20073

[2] SIEGEL R, NAISHADHAM D, JEMAL A. Cancer statistics, 2012. CA Cancer J Clin 2012; 62: 10-29. http://dx.doi. org/10.3322/caac. 20138

[3] ARORA S, BHARDWAJ A, SRIVASTAVA SK, SINGH S, MCCLELLAN $S$ et al. Honokiol arrests cell cycle, induces apoptosis, and potentiates the cytotoxic effect of gemcitabine in human pancreatic cancer cells. PLoS One 2011; 6: e21573. http://dx.doi.org/10.1371/journal.pone.0021573

[4] RUBIN CI, ATWEH GF. The role of stathmin in the regulation of the cell cycle. J Cell Biochem 2004; 93: 242-250. http://dx.doi.org/10.1002/jcb.20187

[5] FERRARI AC, SEUANEZ HN, HANASH SM, ATWEH GF. A gene that encodes for a leukemia-associated phosphoprotein (p18) maps to chromosome bands 1p35-36.1. Genes Chromosomes Cancer 1990; 2: 125-129. http://dx.doi. org/10.1002/gcc. 2870020208

[6] CASSIMERIS L. The oncoprotein 18/stathmin family of microtubule destabilizers. Curr Opin Cell Biol 2002; 14: 18-24. http://dx.doi.org/10.1016/S0955-0674(01)00289-7

[7] SOBEL A. Stathmin: a relay phosphoprotein for multiple signal transduction? Trends Biochem Sci 1991; 16: 301-305. http://dx.doi.org/10.1016/0968-0004(91)90123-D

[8] SAAL LH, JOHANSSON P, HOLM K, GRUVBERGER-SAAL SK, SHE QB et al. Poor prognosis in carcinoma is associated with a gene expression signature of aberrant PTEN tumor suppressor pathway activity. Proc Natl Acad Sci U S A 2007; 104: 7564-7569. http://dx.doi.org/10.1073/pnas.0702507104

[9] CHUNG MK, KIM HJ, LEE YS, HAN ME, YOON S et al. Hedgehog signaling regulates proliferation of prostate cancer cells via stathmin1. Clin Exp Med 2010; 10: 51-57. http:// dx.doi.org/10.1007/s10238-009-0068-7

[10] KARST AM, LEVANON K., DURAISAMY S, LIU JF, HIRSCH MS et al. Stathmin 1, a marker of PI3K pathway activation and regulator of microtubule dynamics, is expressed in early pelvic serous carcinomas. Gynecol Oncol 2011; 123: 5-12. http://dx.doi.org/10.1016/j.ygyno.2011.05.021

[11] BELLETTI B, NICOLOSO MS, SCHIAPPACASSI M, BERTON S, LOVAT F et al. Stathmin activity influences sarcoma cell shape, motility, and metastatic potential. Mol Biol Cell 2008; 19: 2003-2013. http://dx.doi.org/10.1091/mbc.E07-09$\underline{0894}$

[12] NIETHAMMER P, BASTIAENS P, KARSENTI E. Stathmintubulin interaction gradients in motile and mitotic cells. Science 2004; 303: 1862-1866. http://dx.doi.org/10.1126/ $\underline{\text { science. } 1094108}$

[13] MELHEM RF, ZHU XX, HAILAT N, STRAHLER JR, HANASH SM. Characterization of the gene for a proliferation-related phosphoprotein (oncoprotein 18) expressed in high amounts in acute leukemia. J Biol Chem 1991; 266: 17747-17753.

[14] BRATTSAND, G. Correlation of oncoprotein 18/stathmin expression in human breast cancer with established prog- nostic factors. Br J Cancer 2000; 83: 311-318. http://dx.doi. org/10.1054/bjoc.2000.1264

[15] CHEN G., WANG H, GHARIB TG, HUANG CC, THOMAS DG et al. Overexpression of oncoprotein 18 correlates with poor differentiation in lung adenocarcinomas. Mol Cell Proteomics 2003; 2: 107-116. http://dx.doi.org/10.1074/mcp. M200055-MCP200

[16] KOUZU Y, UZAWA K, KOIKE H, SAITO K, NAKASHIMA $\mathrm{D}$ et al. Overexpression of stathmin in oral squamous-cell carcinoma: correlation with tumour progression and poor prognosis. Br J Cancer 2006; 94: 717-723.

[17] MISTRY SJ, ATWEH GF. Therapeutic interactions between stathmin inhibition and chemotherapeutic agents in prostate cancer. Mol Cancer Ther 2006; 5: 3248-3257. http://dx.doi. org/10.1158/1535-7163.MCT-06-0227

[18] CHENG AL, HUANG WG, CHEN ZC, PENG F, ZHANG $\mathrm{PF}$ et al., Identification of novel nasopharyngeal carcinoma biomarkers by laser capture microdissection and proteomic analysis. Clin Cancer Res 2008; 14: 435-445. http://dx.doi. org/10.1158/1078-0432.CCR-07-1215

[19] SALVESEN HB, CARTER SL, MANNELQVIST M, DUTT A, GETZ G et al. Integrated genomic profiling of endometrial carcinoma associates aggressive tumors with indicators of PI3 kinase activation. Proc Natl Acad Sci U S A 2009; 106: 4834-4839. http://dx.doi.org/10.1073/ pnas.0806514106

[20] JEON TY, HAN ME, LEE YW, LEE YS, KIM GH et al. Overexpression of stathmin 1 in the diffuse type of gastric cancer and its roles in proliferation and migration of gastric cancer cells. Br J Cancer 2010; 102: 710-718. http://dx.doi. org/10.1038/sj.bjc. 6605537

[21] ZHENG P, LIU YX, CHEN L, LIU XH, XIAO ZQ et al. Stathmin, a new target of PRL-3 identified by proteomic methods, plays a key role in progression and metastasis of colorectal cancer. J Proteome Res 2010; 9: 4897-4905. http://dx.doi. org/10.1021/pr100712t

[22] KARST AM, LEVANON K., DURAISAMY S, LIU JF, HIRSCH MS et al. Stathmin 1, a marker of PI3K pathway activation and regulator of microtubule dynamics, is expressed in early pelvic serous carcinomas. Gynecol Oncol 2011; 123: 5-12. http://dx.doi.org/10.1016/j.ygyno.2011.05.021

[23] GAN L, GUO K., LI Y, KANG X, SUN L, et al. Up-regulated expression of stathmin may be associated with hepatocarcinogenesis. Oncol Rep 2010; 23: 1037-1043.

[24] HSIEH SY, HUANG SF, YU MC, YEH TS, CHEN TC et al. Stathmin 1 overexpression associated with polyploidy, tumorcell invasion, early recurrence, and poor prognosis in human hepatoma. Mol Carcinog 2010; 49: 476-487.

[25] CHEN YL, UEN YH, LI CF, HORNG KC, CHEN LR et al. The E2F Transcription Factor 1 Transactives Stathmin 1 in Hepatocellular Carcinoma. Ann Surg Oncol 2012; 22

[26] LIVAK KJ, SCHMITTGEN TD. Analysis of relative gene expression data using real-time quantitative PCR and the 2(-Delta Delta C(T)) Method. Methods 2001; 25: 402-408. http://dx.doi.org/10.1006/meth.2001.1262

[27] VERHEY KJ, GAERTIG J. The tubulin code. Cell Cycle 2007; 6: 2152-2160. http://dx.doi.org/10.4161/cc.6.17.4633 
[28] SAAL LH, JOHANSSON P, HOLM K, GRUVBERGER-SAAL SK, SHE QB et al. Poor prognosis in carcinoma is associated with a gene expression signature of aberrant PTEN tumor suppressor pathway activity. Proc Natl Acad Sci U S A 2007; 104: 7564-7569. http://dx.doi.org/10.1073/pnas.0702507104

[29] YUAN RH, JENG YM, CHEN HL, LAI PL, PAN HW et al. Stathmin overexpression cooperates with p53 mutation and osteopontin overexpression, and is associated with tumour progression, early recurrence, and poor prognosis in hepatocellular carcinoma. J Pathol 2006; 209: 549-558. http://dx.doi. org/10.1002/path.2011

[30] GAN L, GUO K, LI Y, KANG X, SUN L et al. Up-regulated expression of stathmin may be associated with hepatocarcinogenesis. Oncol Rep 2010; 23: 1037-1043.

[31] JEON TY, HAN ME, LEE YW, LEE YS, KIM GH et al., Overexpression of stathmin 1 in the diffuse type of gastric cancer and its roles in proliferation and migration of gastric cancer cells. Br J Cancer 2010: 102: 710-718. http://dx.doi. org/10.1038/sj.bjc.6605537

[32] MISTRY SJ, BANK A, ATWEH GF. Targeting stathmin in prostate cancer. Mol Cancer Ther 2005; 4: 1821-1829. http:// dx.doi.org/10.1158/1535-7163.MCT-05-0215

[33] WANG R, DONG K, LIN F, WANG X, GAO P et al. Inhibiting proliferation and enhancing chemosensitivity to taxanes in osteosarcoma cells by RNA interference-mediated downregulation of stathmin expression. Mol Med 2007; 13(11-12): 567-575. http://dx.doi.org/10.2119/2007-00046.Wang

[34] KAVERINA I, STRAUBE A. Regulation of cell migration by dynamic microtubules. Semin Cell Dev Biol 2011;22: 968-974. http://dx.doi.org/10.1016/j.semcdb.2011.09.017

[35] NEMUNAITIS J. STATHMIN 1: a protein with many tasks. New biomarker and potential target in cancer. Expert Opin Ther Targets 2012; 16: 631-634. http://dx.doi.org/10.1517/ $\underline{14728222.2012 .696101}$ 